\title{
The climate change variations in the northern Greater Khingan Mountains during the past centuries
}

\author{
ZHAO Huiying, *GONG Lijuan, QU Huihui, ZHU Haixia, LI Xiufen, ZHAO Fang
}

Heilongjiang Institute of Meteorological Science, Harbin 150030, China

\begin{abstract}
The Greater Khingan Mountains (Daxinganling) are China's important ecological protective screen and also the region most sensitive to climate changes. To gain an in-depth understanding and reveal the climate change characteristic in this high-latitude, cold and data-insufficient region is of great importance to maintaining ecological safety and corresponding to global climate changes. In this article, the annual average temperature, precipitation and sunshine duration series were firstly constructed using tree-ring data and the meteorological observation data. Then, using the climate tendency rate method, moving-t-testing method, Yamamoto method and wavelet analysis method, we have investigated the climate changes in the region during the past 307 years. Results indicate that, since 1707, the annual average temperature increased significantly, the precipitation increased slightly and the sunshine duration decreased, with the tendency rates of $0.06{ }^{\circ} \mathrm{C} / 10 \mathrm{a}, 0.79 \mathrm{~mm} / 10 \mathrm{a}$ and -5.15 $\mathrm{h} / 10 \mathrm{a}$, respectively $(P \leqslant 0.01)$. Since the 21 st century, the period with the greatest increase of the annual average temperature (also with the greatest increase of precipitation) corresponds to the period with greatest decrease of sunshine duration. Three sudden changes of the annual average temperature and sunshine duration occurred in this period while two sudden changes of precipitation occurred. The strong sudden-change years of precipitation and sunshine duration are basically consistent with the sudden-change years of annual average temperature, suggesting that in the mid-1860s, the climatic sudden change or transition really existed in this region. In the time domain, the climatic series of this region exhibit obvious local variation characteristics. The annual average temperature and sunshine duration exhibit the periodic variations of 25 years while the precipitation exhibits a periodic variation of 20 years. Based on these periodic characteristics, one can infer that in the period from 2013 to 2030 , the temperature will be at a high-temperature stage, the precipitation will be at an abundant-precipitation stage and the sunshine duration will be at an less-sunshine stage. In terms of spatial distribution, the leading distribution type of the annual average temperature in this region shows integrity, i.e., it is easily higher or lower in the whole region; and the second distribution type is more (or less) in the southwest parts and less (or more) in the northeast parts. Precipitation and sunshine duration exhibit complex spatial distribution and include four
\end{abstract}

Received: 2015-10-05 Accepted: 2015-12-21

Foundation: National Natural Science Foundation of China, No.41165005; No.40865005

Author: Zhao Huiying (1964-), Professor, specialized in the effect of climate changes on ecosystems. E-mail: zhaohhyy2008@aliyun.com

*Corresponding author: Gong Lijuan (1982-), Engineer, E-mail: footprint05@126.com 
spatial distribution types. The present study can provide scientific basis for the security investigation of homeland, ecological and water resources as well as economic development programming in China's northern borders.

Keywords: climate change; temporal and spatial characteristics; northern Greater Khingan Mountains; sudden change test; period analysis

Forest has a close and complex relationship with climate. Climatic conditions are decisive factors for forest attributes. In September, 2013, Intergovernmental Panel on Climate Change issued the fifth assessment report on climate changes, which pointed out that global climate changes have imposed significant effects on many natural ecosystems on the earth. Especially, the sensitivity of forest ecosystems to global climate changes has led to the accelerated degradation of forest ecosystems on a global scale (IPCC, 2013). Accordingly, the mechanism of interaction between climate changes and forest ecosystems on multiple scales from different aspects is not only a core problem attracting the attention of ecologists and climatologists, but also the focus and a frontier question sharing the concerns of international community currently (Xie et al., 2009; Yang et al., 2012). With regard to the studies on climate changes based on tree ring, the foreign researches have conducted the tree-ring-based climate reconstruction for a long time and many studies were focused on the climate reconstruction based on tree-ring network in many arid and cold regions of North America (Briffa et al., 1998; Cook et al., 2002; D’Arrigo et al., 2005; Yadav et al., 2002). To construct a perfect tree-ring network, more than a hundred of regional tree-ring samples are required, in which temperature, precipitation, drought index and North Pacific Index should be adopted as the factors. Many satisfactory results have already been achieved in climatic sudden change analysis. The investigations on the climate changes in high-latitude regions of China over a century have started late, but with a high starting point. In these studies, the researches not only paid attention to the variation analysis from single meteorological factor (Cai et al., 2010; Gou et al., 2013; Shi et al., 2010), but also explored the characteristics and effects of regional climate changes (Lu et al., 2014; Sun et al., 2012; Wang et al., 2012; Yu et al., 2005). These achievements have laid solid theoretical basis and technical supports for revealing the evolvement rules of climate changes in the Greater Khingan Mountains (GKM), a high- latitude cold region.

The Greater Khingan (GKM) region is a first-grade National Nature Ecological Reserve, which is located at the southern margin of the permafrost of Eurasia (Wu et al., 2014). The GKM is in the alpine region, an environmental sensitive area in Northeast Asia. This region is abundant in forest resources, including China's only primeval cold-temperature bright coniferous forest with the largest area and best preserve, with the constructive species of Larix gmelinii and Mongolian pine. Compared with the other forest regions in China, the GKM exhibits a series of unique features in terms of soil, disturbance regime, climate and vegetation. Few systematic studies were conducted on the climate changes in the northern GKM; moreover, due to the limitations in high-latitude data density and series length, the research achievements in regional climate changes lack of systematicness and comprehensiveness. Therefore, using the reconstructed data series of annual average temperature, precipitation and sunshine duration based on tree-ring width during the period from 1707 to 2013 in the northern GKM, we conducted a systematic investigation on temporal and spatial 
characteristics of the climate changes in the northern GKM, so as to further determine the rules of climate changes and identify the change characteristics. The present study aims to gaining an in-depth insight into the climate changes in this alpine region, which can not only lay solid foundations for the climate change investigations in the whole high-latitude region, but also provide significant scientific and application values for the homeland, ecological and water resource security as well as economic development programming in China's northern borders.

\section{Materials and method}

\subsection{Data acquisition and a general introduction to the study region}

The northern GKM was selected as a case in the present study, with the latitude ranging from $50^{\circ} 10^{\prime}$ to $53^{\circ} 30^{\prime} \mathrm{N}$ and the longitude ranging from $119^{\circ} 40^{\prime}$ to $127^{\circ} 22^{\prime} \mathrm{E}$. It is bounded on the north and northeast by the Heilongjiang River while on the west and northwest by the Erguna River, bordering to East Siberia and Far East in Russia across the two rivers each; the southeast extends to the line along Heihe City and Nenjiang County and is connected to the Lesser Khingan Mountains (Range). The study region covers an area of approximately $16.22 \times 10^{4} \mathrm{~km}^{2}$ (exceeding the area of Liaoning Province). In terms of vegetation regionalization, it is an independent cold-temperate coniferous forest zone and characterized by a cold-temperate continental monsoon climate (Zhou, 1991). From south (east) to north (west), the annual temperature decreases from $-1-0^{\circ} \mathrm{C}$ to $-5--4^{\circ} \mathrm{C}$, the annual temperature range increases from $35^{\circ} \mathrm{C}$ to $52^{\circ} \mathrm{C}$, and the annual precipitation decreases from $500-700 \mathrm{~mm}$ to below $200 \mathrm{~mm}$ (He et al., 2013). The soils are mainly dark brown coniferous forest soils, and the vegetation cover is the Khingan flora, in which the Khingan larch trees occupy a large proportion in tree species, followed by Mongolian pine and dragon spruce.

In the present study, the climatological data of the northern GKM consists of the climatic factors inverted by the tree-ring width data from 1707 to 2007 and the climatological observation data from 1961 to 2013. After being tested, the historical climatological data series are from 1707 to 2013 (lasting 307 years), with the climatic factors of annual average temperature, precipitation and sunshine duration. It should be noted that the data of all these climatic factors were calculated by averaging the data from April in the current year to March in the next year. According to requirements in the present study, these data series include three sections (Li et al., 2011; Li et al., 2014): specifically, from 1707 to 1960, since no instrument-measured data in this region, the climatological data were acquired by inverting the observation data from Erguna Municipal Meteorological Station $\left(50^{\circ} 15^{\prime} 0^{\prime \prime} \mathrm{N}\right.$, $120^{\circ} 10^{\prime} 48^{\prime \prime} \mathrm{E}$, with a height of $\left.581 \mathrm{~m}\right)$ and Genhe Meteorological Station $\left(50^{\circ} 46^{\prime} 48^{\prime \prime} \mathrm{N}\right.$, $121^{\circ} 31^{\prime} 12^{\prime \prime} \mathrm{E}$, with a height of $779 \mathrm{~m}$ ) through the constructed regression equations (these two meteorological stations are at the nearest distance from Angelin Forest Farm $\left(51^{\circ} 25^{\prime} 12^{\prime \prime} \mathrm{N}, 120^{\circ} 54^{\prime} 51^{\prime \prime} \mathrm{E}\right)$ and Xinqing Forest Farm $\left(51^{\circ} 23^{\prime} 3^{\prime \prime} \mathrm{N}, 120^{\circ} 48^{\prime} 38^{\prime \prime} \mathrm{E}\right)$ and have the same underlying surfaces and the tree-ring width data were collected in these two forest farms); from 1961 to 2007, the climatological data were calculated by averaging the data in Angelin and Xinqing tree-ring width inversion stations and the observation data of 11 meteorological stations (the station density was added); from 2008 to 2013, the climatological data were the average values of the observation data collected from 11 meteorological sta- 
tions (the tree-ring width data were collected in 2007). Since the Beijicun Station was built later and the data series are incomplete, the data were deleted (only used for matching).

Based on the standard tree-ring chronology and meteorological data, we have investigated the meteorological data during the period from 1707 to 2007 using regression method (Qu et al., 2016). As stated in the previous research results, the constructed quantitative relationship between tree-ring width and meteorological factors could pass the credibility test. Moreover, the obtained 307-year meteorological data series could pass the consistency check (see details in Qu et al., 2016). More importantly, compared with the specific meteorological data, we are more concerned with the data series length, the density of the acquired data, the fluctuation changes of various meteorological factors, and the characteristics of regional climate changes. Therefore, the processing meteorological data series in this article can meet the technical requirements that the tree ring can be used for replacing meteorological data, and the meteorological series have certain reliability in the applications of present study. Figure 1 illustrates the distributions of tree-ring sample points and meteorological stations.

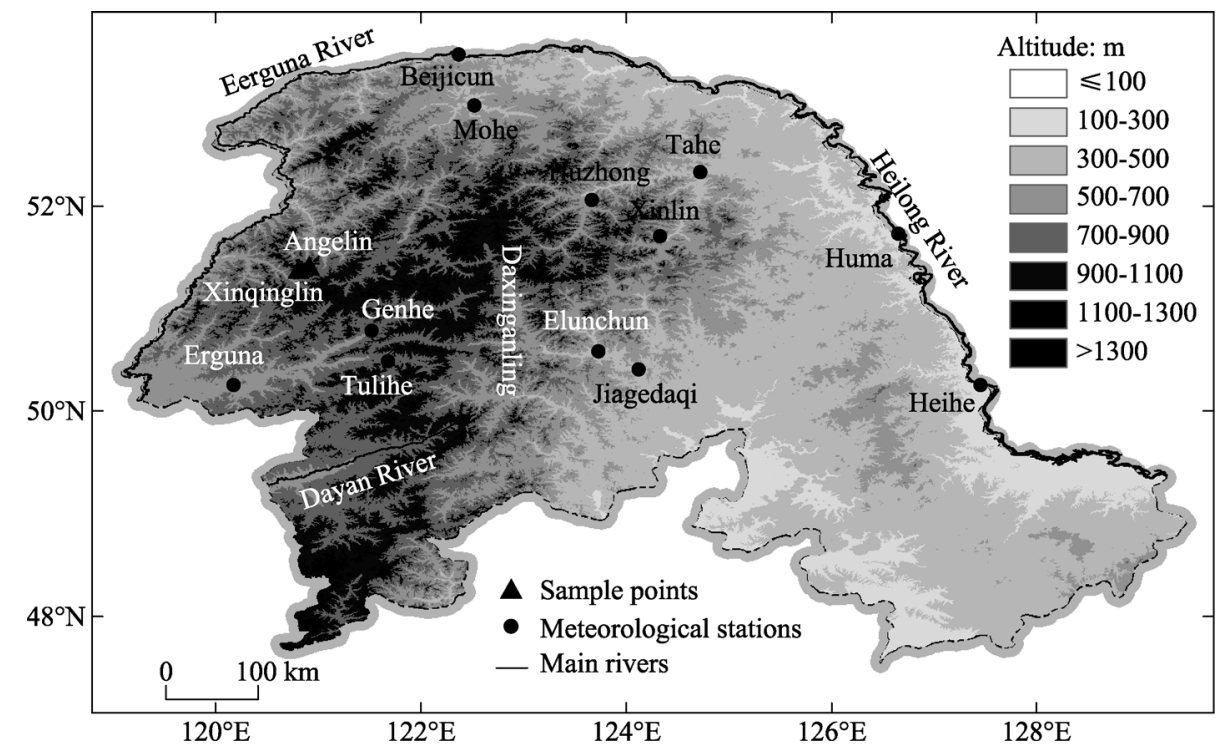

Figure 1 Illustration of the geological positions of the northern Greater Khingan Mountains and the distributions of meteorological stations and tree-ring sampling points

\subsection{Method}

\subsubsection{Wavelet analysis}

The descriptions of the time series' pattern evolution characteristics and the position in each period at each moment using wavelet theory can enhance the short-time Fourier transform's ability in dealing with practical problems and has become a new method of analyzing the series' time-varying characteristics.

Assuming a wavelet function that satisfies a certain condition, the wavelet transform of the time series can be described as:

$$
W_{f}(a, b)=|a|^{-\frac{1}{2}} \int_{R} f(t) \bar{\Psi}\left(\frac{t-b}{a}\right) \mathrm{d} t
$$


where $W_{f}(a, b)$ denotes wavelet transform or wavelet coefficient, and varies with the variations of $a$ and $b$ ( $a$ denotes a frequency parameter and reflects the length of wavelet period, $a>0$, while $b$ denotes a time parameter and reflects the wave's translation over time). The wavelet coefficient $W_{f}(a, b)$ on different time scales (periods, with the unit of year, the same below) can reflect the system's variation characteristics on different time scales. The turning point between positive and negative wave coefficients corresponds to the sudden change point. The greater the wavelet coefficient, the more significant the variations on this time scale (Ge et al., 2013; Guo et al., 2013; Zhao et al., 2012).

Mexican Hat Function can be expressed as:

$$
\Psi(t)=\left(1-t^{2}\right) e^{\left(-t^{2} / 2\right)}
$$

The wavelet variance test was conducted for determining the main periods of several data series of annual average temperature, precipitation and sunshine duration:

$$
W_{p}(a)=\int_{-\infty}^{\infty}\left|W_{f}(a, b)\right|^{2} d b
$$

where $W_{p}(a)$ denotes the wavelet variance. On a certain time scale, wavelet variance reflects the periodic fluctuation intensity of the time series on this scale. The scale corresponding to the peak value thus can be regarded as the main time scale of this series, i.e., the main period.

\subsubsection{Moving t-test (MTT)}

The principle of moving t-test (MTT) is detailedly described below. The sudden change can be tested according to the fact whether the difference exists between two sets of sample average values. For a series $x$ with the total sample size of $n$, a certain moment can be artificially set as the datum point, and two sub-series before and after this datum point with the length of $n_{1}$ and $n_{2}$ (generally $n_{1}=n_{2}$ ) are selected for moving calculation. Then, a statistic series of $\mathrm{t}$ can be acquired. The critical value $t_{\alpha}$ can be determined by the given quantitative level. If $|t|<t_{\alpha}$, the two sub-series before and after this datum point are considered to be with no significant difference; otherwise, it can be assumed that the sudden change occurs at the datum point. MTT method can be expressed as:

$$
t=\frac{\bar{x}_{1}-\bar{x}_{2}}{s \cdot \sqrt{\frac{1}{n_{1}}+\frac{1}{n_{2}}}}, \quad s=\sqrt{\frac{n_{1} s_{1}^{2}+n_{2} s_{2}^{2}}{n_{1}+n_{2}-2}}
$$

where $s_{1}$ and $s_{2}$ are the standard deviations of two sub-series. In this article, $n=307$ years, $n_{1}$ and $n_{2}$ were set as 20 years, and $\alpha=0.01$ was adopted as the significance level of sudden change judgment, i.e., in the continuous years at different periods passed the test of significance level, the year with the greatest value of $t$ was selected as the strongest sudden-change year.

\subsubsection{Yamamoto method (YAMA)}

Using MTT, since the moving step size was artificially set (Sun et al., 2005; Zhang et al., 2015), the sudden change point may drift. In the present study, the sudden change analysis 
was firstly conducted using MTT; the test was conducted on the detected sudden change point (if exists) using Yamamoto method (YAMA); if the results using two methods are consistent or approach with each other, the sudden change year can be identified.

Using YAMA method, the significant difference of the average values at different times can be tested by the signal to noise ratio $\left(\mathrm{S}_{\mathrm{NR}}\right)$ :

$$
R_{S N}=\frac{\left|\bar{x}_{1}-\bar{x}_{2}\right|}{S_{1}+S_{2}}
$$

where $\bar{x}_{1}, \bar{x}_{2}, S_{1}$ and $S_{2}$ denote the average values and variances at two different times. $n_{1}$ and $n_{2}$ of the time periods for comparison can be set in accordance with requirements, whose values affect the significance level of $R_{S N}$. Generally, for a continuous random variable, the subsections are set uniformly, i.e., $n=n_{1}=n_{2}$. In the present study, $n$ was set as 20 , if $R_{S N}>0.60$, it exceeds the significance level of $\alpha=0.01$, and the point can be regarded as the sudden change point; if $R_{S N}>0.79$, the point can be regarded as the strong sudden change point.

\subsubsection{Climate tendency rate method}

To calculate the climate tendency rate of the climatic series in the northern GKM (Zhao et al., 2008), the year $t$ was adopted as the time factor and the climatic factor $x$ was adopted as the simulation objection; then the linear regression equation between $x$ and $t$ was constructed as: $x(t)=c+b t$, in which $c$ and $b$ are the coefficients to be confirmed. Specifically, $b$ denotes the tendency of climatic factors. If $b>0$, the climatic factors exhibit rising trends; if $b \leqslant 0$, the climatic factors exhibit downtrends. Therefore, $b \times 10$ is referred to as the climate tendency rate, with the unit of the ratio of the unit of climatic factors to 10 years.

\subsubsection{Empirical orthogonal function (EOF) analysis}

EOF analysis focuses on the matrix data's structural characteristics and aims to extract the primary characteristic quantity of data. It is a common temporal and spatial characteristic distribution method. The annual average temperature, precipitation and sunshine duration were described as matrices: $X_{m \times n}(m=1,2, \ldots, 13 ; n=1,2, \ldots, 43)$. After standardization processing, these matrices can be decomposed into several new matrices (Huang et al., 2013):

$$
N_{m \times n}=V_{m \times p} T_{p \times n}
$$

where $V_{m \times p}$ denotes the spatial characteristic vector and $T_{p \times n}$ denotes the time coefficient. When $p=n=43$, the information of all the meteorological stations can be completely described. It means that the primary variation characteristics of climatic factors can be roughly expressed using the first several characteristic vectors.

\section{Results and analysis}

\subsection{Interannual and interdecadal variation characteristics of climate changes}

Used climate tend rate, MTT, YAMA and Mexican Hat wavelet function method, the changing trend, abrupt change test and periodic change of climate series in northern GKM were analyzed. 


\subsubsection{Tendency analysis of climate series}

Figure 2 displays the climate series of the northern GKM from 1707 to 2013 and the variation curves after the moving average with the moving step size of 11 years. The climate tendency rate was calculated by the first-order linear tendency equation. As shown in Figure 2a, the annual temperature varies between -6.99 and $-1.28^{\circ} \mathrm{C}$, with a climate tendency rate of $0.06^{\circ} \mathrm{C} / 10 \mathrm{a}(P \leqslant 0.01)$. Before the 20 th century, the variation is slight, and the annual average temperature is approximately $-5.08^{\circ} \mathrm{C}$. After the 20 th century, the annual average temperature increases gradually in the fluctuation; especially, a leap temperature increase appeared in the 1930s. Then the increase of the annual average temperature is smooth again, and this region entered into a continued warming period since the 1950s. During the period from 1951 to 2013 , the annual average temperature is approximately $-3.22^{\circ} \mathrm{C}$, which exceeds by $1.86^{\circ} \mathrm{C}$ compared with the data in the 18 th and 19 th centuries. Moreover, this region is stall in a warming stage. As shown in Figure $2 b$, the precipitation varies between 344.86 and $690.16 \mathrm{~mm}$, with a climate tendency rate of $0.79 \mathrm{~mm} / 10 \mathrm{a}(P \leqslant 0.01)$. The precipitation almost exhibits no variations and only increases slightly. During the period from 1707 to the end of the 19th century, the precipitation exhibits slight fluctuation changes, with the average precipitation of $436.71 \mathrm{~mm}$. In the early 20 th century, a low-precipitation-value period occurs, with the duration time less than 25 years. By the 1930 s, the precipitation increases slightly and the fluctuation amplitude of precipitation increases significantly by the 1980s. During the period from 1981 to 2013 , the annual average precipitation is $480.46 \mathrm{~mm}$, exceeding by $43.74 \mathrm{~mm}$ compared with the value in the early 20th century. Moreover, the precipitation is in a slow increasing stage. As shown in
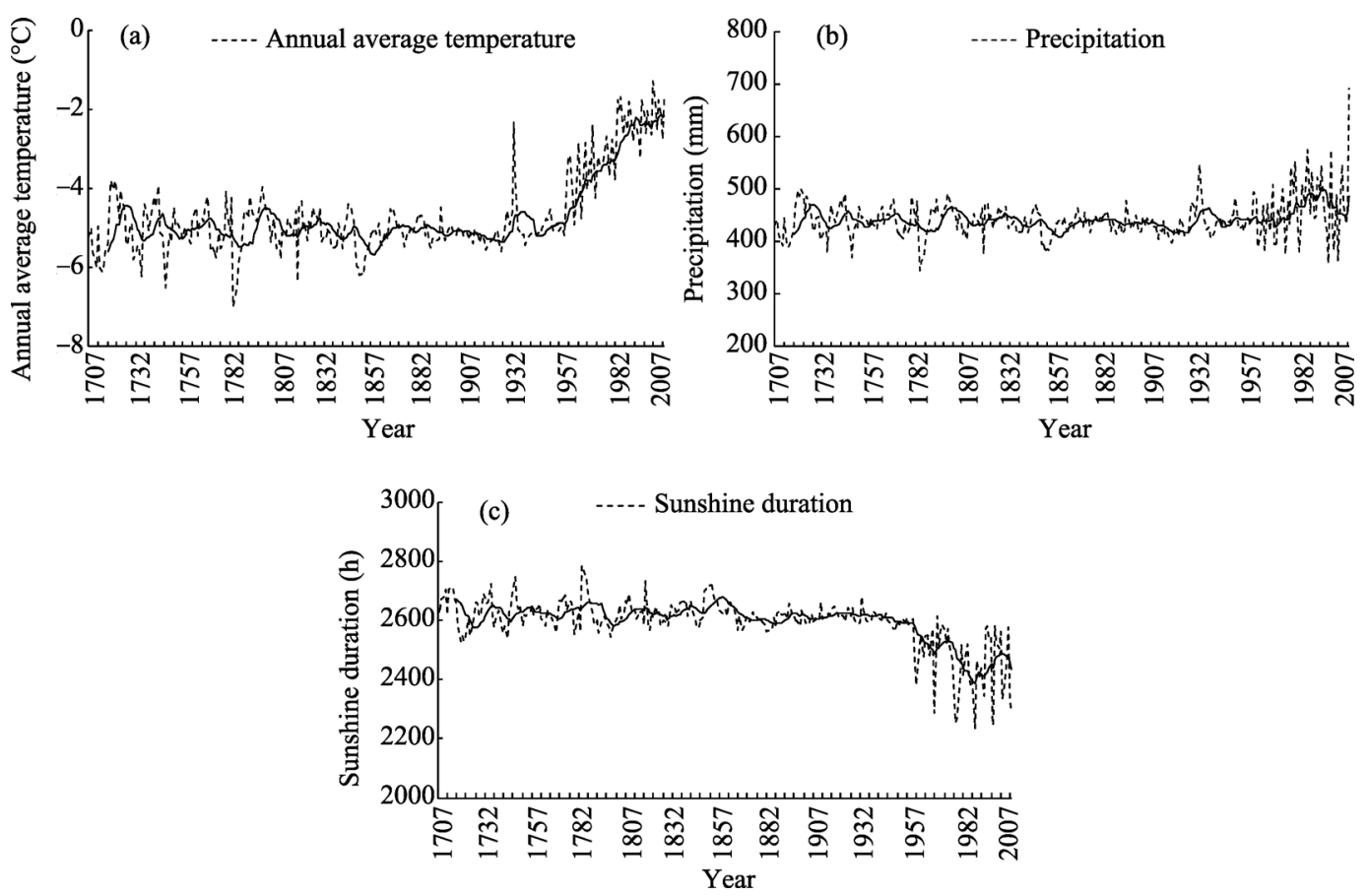

Figure 2 Interannual variation tendency of the climatic series in the northern Greater Khingan Mountains during the period from 1707 to 2013 (a. annual average temperature; b. precipitation; c. sunshine duration, the same below) 
Figure 2c, the sunshine duration in the northern GKM is $2233.36-2783.72 \mathrm{~h}$, with a climate tendency rate of $-5.15 \mathrm{~h} / 10 \mathrm{a}(P \leqslant 0.01)$. Before the $1950 \mathrm{~s}$, the sunshine duration exhibits no obvious variation tendency; after the 1950s, it decreases significantly, which at least shows that the sprinkles and hazy weathers increase gradually.

Table 1 lists the variation of climate series in the northern GKM over different centuries from 1707 to 2013. One can observe that, the annual average temperature exhibits no distinct variations in the 18th and 19th centuries; but increases significantly in the 20th century. The annual average temperature in the 20th century is $0.83^{\circ} \mathrm{C}$ higher than the value in the 19 th century, with the warming amplitude of $0.32^{\circ} \mathrm{C} / 10 \mathrm{a}$. The results also passed the significance tests. The precipitation in this region decreases slightly in the 19th century, which is $3.73 \mathrm{~mm}$ lower than the value in the 18 th century. After 1900 , the precipitation increases gradually, with a climate tendency rate of $6.04 \mathrm{~mm} / 10 \mathrm{a}(P \leqslant 0.01)$. During the period from 2000 to 2013 , the precipitation is the greatest. On the whole, the sunshine duration decreases in this region. The sunshine duration from 1800 to 1999 is $2.75 \mathrm{~h}$ lower than the value in the 18th century; after 1901, the sunshine duration decreases significantly, with a climate tendency rate of $-23.27 \mathrm{~h} / 10 \mathrm{a}(P \leqslant 0.01)$. From 2000 to 2013 , the sunshine duration decreases most remarkably, and the sunshine duration during this period is reduced by $100.14 \mathrm{~h}$ compared with the value in the 20th century.

Table 1 Variation of climate series in the northern Greater Khingan Mountains from 1707 to 2013

\begin{tabular}{|c|c|c|c|c|c|c|}
\hline \multirow[b]{2}{*}{ Year } & \multicolumn{2}{|c|}{ Annual average temperature } & \multicolumn{2}{|c|}{ Precipitation } & \multicolumn{2}{|c|}{ Sunshine duration } \\
\hline & $\begin{array}{l}\text { Average } \\
\text { value } /{ }^{\circ} \mathrm{C}\end{array}$ & $\begin{array}{c}\text { Climate tendency } \\
\text { rate } /{ }^{\circ} \mathrm{C} / 10 \mathrm{a}\end{array}$ & $\begin{array}{c}\text { Average } \\
\text { value } / \mathrm{mm}\end{array}$ & $\begin{array}{l}\text { Climate tendency } \\
\text { rate } / \mathrm{mm} / 10 \mathrm{a}\end{array}$ & $\begin{array}{l}\text { Average } \\
\text { value/h }\end{array}$ & $\begin{array}{c}\text { Climate ten- } \\
\text { dency rate } / \mathrm{h} / 10 \mathrm{a}\end{array}$ \\
\hline $1707-1799$ & -5.04 & 0.02 & 438.64 & 0.85 & 2626.87 & -1.44 \\
\hline $1800-1899$ & -5.11 & -0.01 & 434.91 & -0.33 & 2624.13 & $-2.80 *$ \\
\hline 1900-1999 & -4.28 & $0.32 * *$ & 446.50 & $6.04 * *$ & 2551.71 & $-23.27 * *$ \\
\hline $2000-2013$ & -2.15 & -0.01 & 470.44 & 116.57 & 2451.57 & -116.22 \\
\hline
\end{tabular}

Note: * denotes the results passed the significant test at the level of $\mathrm{P}=0.05$; $*$ denotes the results passed the significant test at the level of $\mathrm{P}=0.01$

\subsubsection{Sudden change detection of climatic series}

Using MTT and YAMA method, the sudden change detection was performed on the annual average temperature, precipitation and sunshine duration series during the period from 1707 to 2013 in the northern GKM, and the reliable sudden change years were determined through comparisons. Table 2 lists the results of years that passed the significance test at the level of $P \leqslant 0.01$. One can conclude that the annual average temperature exhibits sudden changes in 1866, 1960 and 1987, in which the sudden change in 1960 is most intensive; the precipitation exhibits sudden changes in 1867 and 1927, in which the sudden change in 1867 is most intensive; the sunshine duration exhibits sudden changes in 1866, 1960 and 1978, in which the sudden change in 1866 is most intensive. The years with most strong sudden changes of precipitation and sunshine duration are basically consistent with the years with sudden changes of annual average temperature, indicating that the climate in this region really underwent sudden changes or transitions in the mid-1860s. The sudden change directions were further determined using MTT analysis. It can be observed that annual average temperature 
and sunshine duration share the same sudden change points but different sudden change directions. The annual average temperature and precipitation varied suddenly from less to more while the sunshine duration varied suddenly from more to less, which are in good consistency with the variation tendencies of the above climatic series.

Table 2 Sudden change years of the climatic series in the northern Greater Khingan Mountains from 1707 to 2013

\begin{tabular}{lccccccccc}
\hline \multicolumn{1}{c}{ Factors } & Methods & \multicolumn{7}{c}{ Sudden change years } \\
\hline $\begin{array}{l}\text { Annual average } \\
\text { temperature }\end{array}$ & MTT & 1771 & 1788 & 1846 & 1866 & 1960 & 1987 & \\
& YAMA & - & - & - & 1866 & 1960 & 1987 & \\
& MTT & 1771 & 1788 & 1847 & 1867 & 1900 & 1908 & 1927 & 1974 \\
Precipitation & YAMA & - & - & - & 1867 & - & - & 1927 & - \\
& MTT & 1771 & 1788 & 1866 & 1887 & 1934 & 1960 & 1978 & - \\
$\begin{array}{l}\text { Sunshine } \\
\text { duration }\end{array}$ & YAMA & - & - & 1866 & - & - & 1960 & 1978 \\
\hline
\end{tabular}

\subsubsection{Periodic variation of climatic series}

Figure 3 displays the Mexican Hat wavelet analysis results of the climatic series from 1707 to 2013, in which the negative isolines were denoted by the dash lines and represent that the factor values are comparatively lower, and the positive or zero isolines were denoted by the solid lines and represent that the factor values are comparatively greater. As shown in Figure $3 \mathrm{a}$, the periodic oscillation of annual average temperature is intensive on a time scale below 10 years, exhibiting no obvious rules; as the time scale increases, the oscillations show obvious periodic rules on the time scale of 20-25 years, and the fluctuation variations on the calculated time domain can be observed, i.e., the annual average temperatures are sometimes lower and sometime higher and totally 8 alternations of warming and cooling occurred in this region. Moreover, the isolines of annual average temperature have still not been closed by 2013, suggesting that this region is in a warming period for some time to come. As shown in Figure 3b, the periodic oscillation of precipitation is also intensive on a time scale below 10 years, exhibiting no obvious rules; with the increase of time scale, the obvious rules can be observed in the periodic oscillation on the time scale of 20-25 years and totally 9 alternations of drying and wetting occurred in this region. Similarly, isolines of precipitation have still not been closed by 2013, suggesting that the precipitation in this region will be slightly more for some time in the future. As shown in Figure 3c, on the time scale of 25-30 years, the sunshine duration in this region shows significant periodic oscillations and totally 10 alternations of sunny and rainy can be observed. Until 2013, the isolines of sunshine duration have still not been closed, suggesting that the sunshine duration will be slightly less for some time in the future.

Figure 4 displays the period analysis on the climatic series in the northern GKM during the period from 1707 to 2013 using the variance of wavelet coefficient. One can observe that, from 1707 to 2013, the wavelet variance of annual average temperature is 25 years; the wavelet variance of precipitation reaches a peak at 20 years, i.e., the primary period of the precipitation variation is 20 years; the sunshine duration variations are mainly the oscillations with the quasi-period of 25 years. According to the periodic characteristics, one can speculate that the annual average temperature will be in a wavelet period of continued 
warming from 2013 to 2030 , the precipitation will be in a wavelet period characterized by slightly more precipitation from 2013 to 2029, and the sunshine duration will be in a wavelet period characterized by slightly less duration from 2013 to 2034. In other words, during the
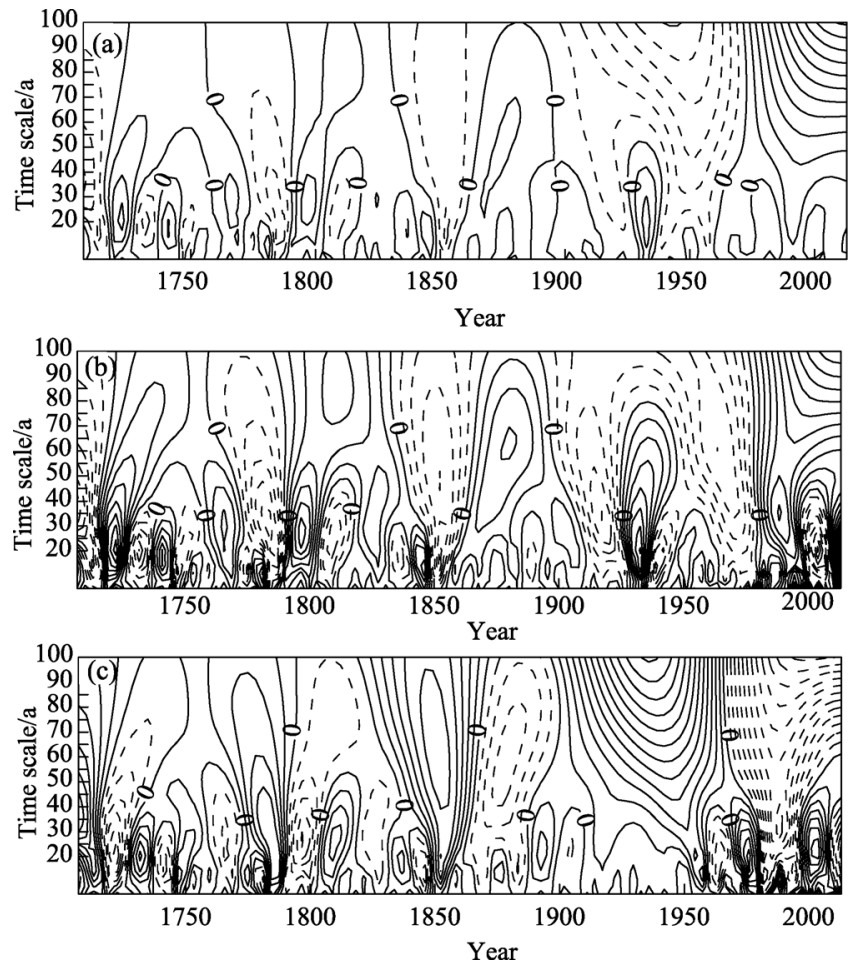

Figure 3 Wavelet analysis of climatic series in the northern Greater Khingan Mountains
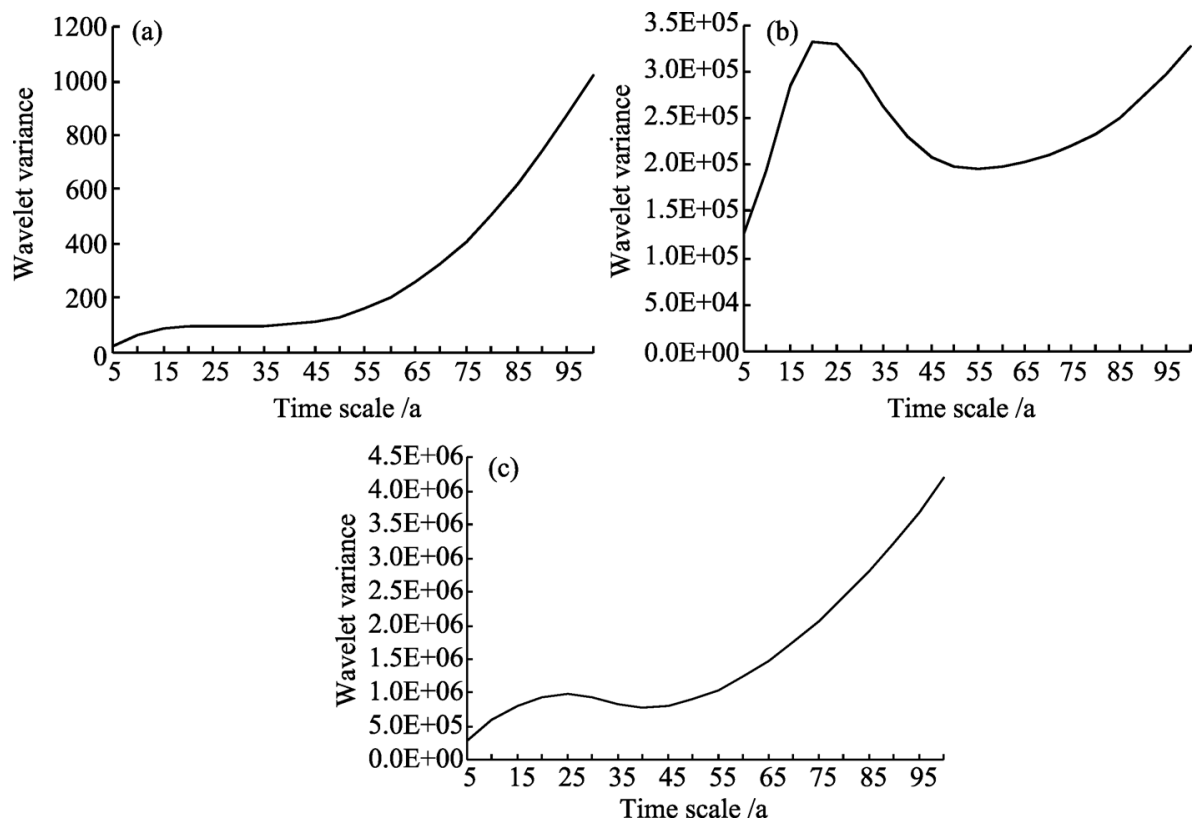

Figure 4 Wavelet variances of climatic series in the northern Greater Khingan Mountains 
period from 2013 to 2030, the annual average temperature will be in a slightly-higher period, the precipitation will be in a slightly-more period and the sunshine duration will be in a slightly-less period.

\subsection{Spatial analysis of climate changes}

To analyze the spatial climate changes in the northern GKM, standardization processing and EOF analysis were conducted on the climatic series in this region, as the results presented in Figures 5-7.
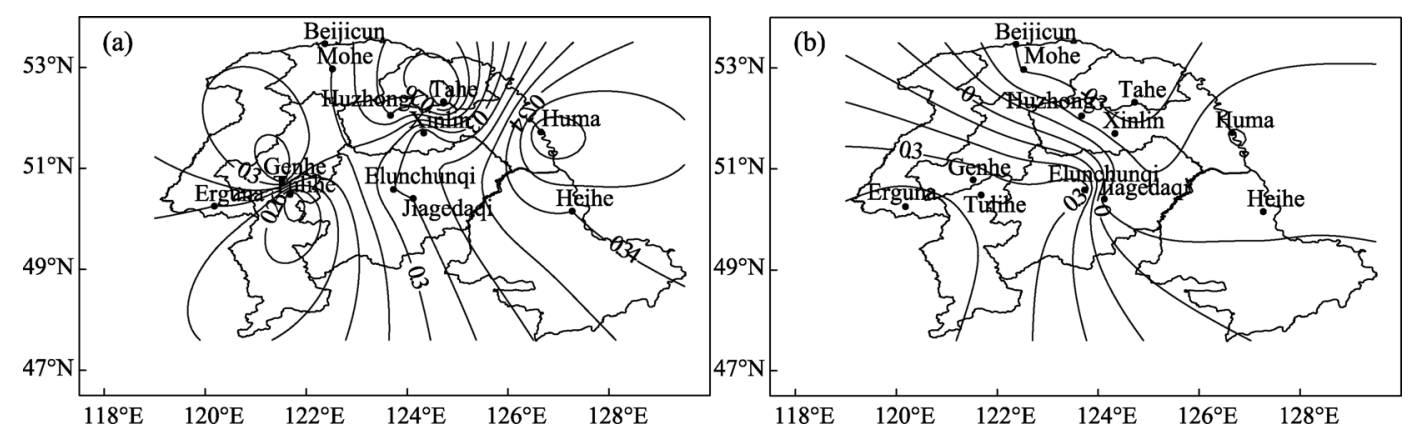

Figure 5 Eigenvector fields of annual average temperature in the northern Greater Khingan Mountains (a. The first eigenvector field; $b$. The second eigenvector field)
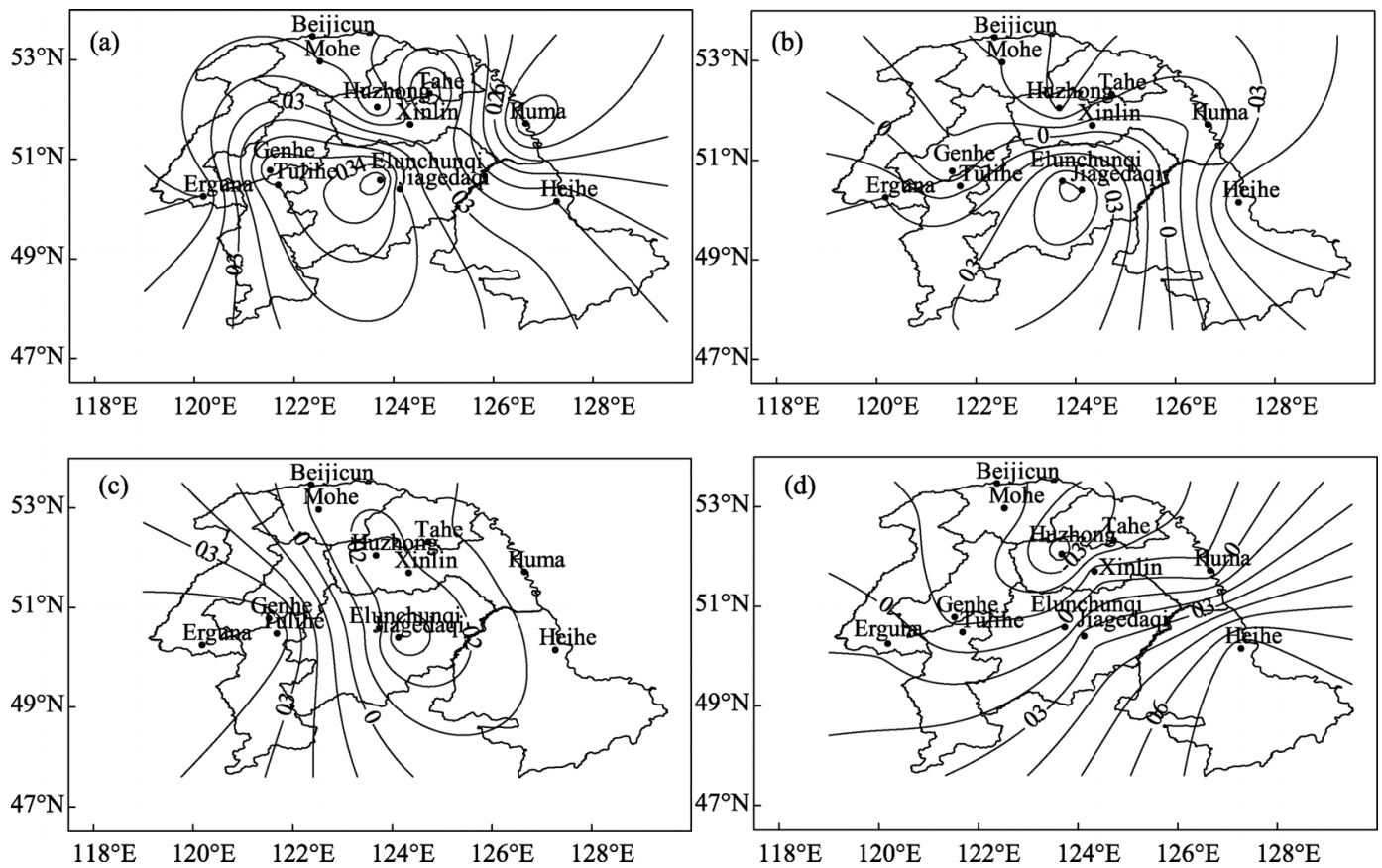

Figure 6 Eigenvector fields of precipitation in the northern Greater Khingan Mountains

(a. The first eigenvector field; b. The second eigenvector field; c. The third eigenvector field; d. The fourth eigenvector field, the same below)

As shown in Figure 5, after EOF expansion on the annual average temperature series, the variance contribution rate of the first eigenvector can reach up to $82.8 \%$; the accumulated 

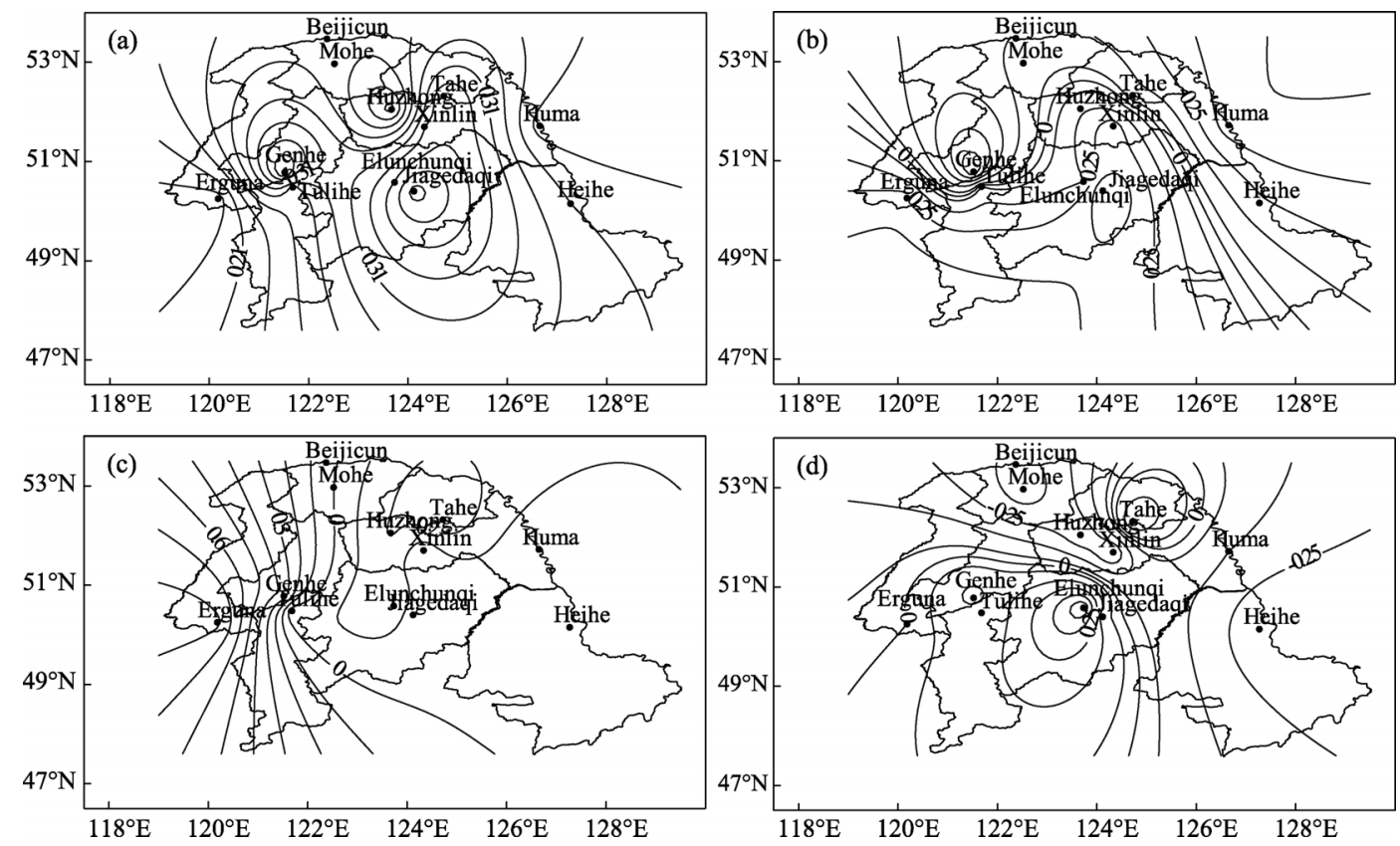

Figure 7 Eigenvector fields of sunshine duration in the northern Greater Khingan Mountains

variance contribution rate of the first two eigenvectors is as high as $93.3 \%$, suggesting that the first two eigenvectors can represent the variation of annual average temperature in this region. The typical field corresponding to the first eigenvector is positive and shows the consistency of annual average temperature variation in this region. As displayed in this typical field, the high-value distribution is concentrated along the Huma-Heihe line, and the eigenvectors values decrease gradually to the west and north; the secondary- high-value distribution is at the center of Genhe. The results demonstrate that, in these two regions of the northern GKM, the annual average temperature variation rates are relatively large; these two regions are also the sensitive regions to temperature changes. The typical field corresponding to the second eigenvector shows the variation characteristics that the southwest part is positive and the northeast part is negative. Zero-value lines are extended towards the northwest direction through Jiagedaqi and Elunchunqi, which represent the second temperature types in the study region. This type shows that the annual average temperature in this region shows the pattern characteristics of higher in the southwest part and lower in the northeast part or lower in the southwest part and higher in the northeast part.

Figure 6 displays the EOF analysis results of the precipitation series in the northern GKM. The accumulated variance contribution rate of the first four eigenvectors can reach up to $83.2 \%$, suggesting that the first four eigenvectors can roughly represent the precipitation in the study region. These four eigenvectors were selected as the four basic distribution types in the study region, and thereby the precipitation in the study region can be classified into four types, namely, more (or less) in the whole region; more (or less) in the central region and less (or more) in the northeastern region; more (or less) in the eastern region and less (or more) in the western region; and more (or less) in the southern region and less (or more) in the northern region. The contribution rate of the first eigenvector to the total variance is up 
to $55.9 \%$, and the typical field corresponding to the first eigenvector can be regarded as the most important typical field reflecting the precipitation variations in the study region. All this typical field is positive, i.e., the whole region is rainy or rainless and can be classified as the first distribution type. The high-value distribution is at the center of Elunchunqi, and the value decreases gradually to the north and east, reflecting that the region's precipitation varies greatly. The contribution rate of the second eigenvector to the total variance is up to $11.2 \%$, and zero-value isolines pass through Yilehuli Mountain and GKM. In terms of spatial distribution, the positive value region is located at the center of Elunchunqi that are surrounded by two mountains while the negative value region is located in the eastern Yilehuli Mountain and the northern GKM. The third eigenvector corresponds to the type of more (or less) in the eastern region and less (or more) in the western region, with the variance contribution rate of $8.8 \%$. In terms of spatial distribution, the negative values in the eastern regions increase gradually towards the west, with the negative-value center in the Elunchunqi, i.e., the spatial pattern is characterized by the reverse variations between west and east. The contribution rate of the fourth eigenvector to the total variance is up to $7.4 \%$. An opposed phase between north and south can be observed. A negative-value center exists in the north of Huzhong while the positive-value center is located in the south of Heihe, reflecting the fourth type of more (or less) in the southern region and less (or more) in the northern region. In other words, in this region, the precipitation is characterized by the reverse variations between south and north.

Figure 7 displays the EOF analysis results of the sunshine duration series in the northern GKM. The accumulated variance contribution rate of the first four eigenvectors can reach up to $85.0 \%$, i.e., the first four eigenvectors can reasonably represent the spatial abnormal distribution of sunshine duration in the study region. The spatial distribution of the first eigenvector is characterized by the positive values in the whole region and in-phase distribution, suggesting that the spatial distribution of sunshine duration in the study region is mainly the consistency-type, i.e., the sunshine duration is easily more or less in the whole region. The maximum-value center is located at the center of Elunchunqi and the second high-value center is located at the center of Genhe. Since the contribution rate the first eigenvector to the total variance is up to $54.6 \%$, more or less sunshine duration in the whole region is the leading spatial distribution type in the study region. The contribution rate of the second eigenvector to the total variance is up to $14.0 \%$, suggesting that the variation type corresponding to the second eigenvector is also a typical spatial distribution of sunshine duration variation. This distribution type uses the Yilehuli Mountain and the GKM as the boundary. The values in the southern parts are positive while the values in the northern parts are negative. The positive-value center is located at the center of Elunchunqi, while the negative-value center is located at the center of Genhe. This spatial distribution is mainly affected by the geological characteristics. The contribution rate of the third eigenvector to the total variance is up to $9.3 \%$. On the whole, the spatial distribution took the Mohe-Tulihe line as the boundary; the values in the eastern parts are negative while the values in the western parts are positive. This is a typical more (or less) in the eastern region and less (or more) in the western region. The greatest positive-value center is in the southern Eerguna while the greatest negative-value center is located in Tahe. The fourth eigenvector field varied greatly from the first three eigenvector fields. In terms of spatial distribution, the values in the mid- 
dle parts are positive while the values in the eastern and western parts are negative. The positive-value center is located at the center of Jiagedaqi and Tahe. The contribution rate of the fourth eigenvector to the total variance is up to $7.1 \%$, i.e., the fourth eigenvector reflects the fourth distribution type of sunshine duration in this study region.

\subsection{Comparisons with the other research results}

Table 3 lists the comparisons between the present research results and the results for Northeast China during the period from 1951 to 2007 as described by $\mathrm{Fu}$ et al. (2009). One can observe that, during the past 60 years, the warming tendency in the northern GKM is consistent with the warming tendency in Northeast China, with the annual average temperature tendency rates of $0.54^{\circ} \mathrm{C} / 10 \mathrm{a}$ and $0.60^{\circ} \mathrm{C} / 10 \mathrm{a}$, respectively; the precipitations in the northern GKM and Northeast China both exhibit no obvious variation, with the precipitation tendency rates of $5.67 \mathrm{~mm} / 10 \mathrm{a}$ and $-0.27 \mathrm{~mm} / 10 \mathrm{a}$, but the variation tendencies are different during this period. Temperature and precipitation show a slight difference in spatial distributions, with almost identical distribution characteristics. By comparing the results from 1989 to 2007 with the results from 1971 to 1988 , one can observe that spatial distributions of annual average temperature variations are basically identical, with the temperature increasing amplitudes of $0.67-1.73^{\circ} \mathrm{C}$ and $0.98^{\circ} \mathrm{C}$, respectively. As described by $\mathrm{Fu}$ et al. (2009), the temperature increasing amplitudes are slightly lower except the results in the northern GKM, i.e., certain differences can be observed. The results fit well the tendency of global warming, which is due to the multiplication of greenhouse gases and the variation of solar radiation.

Table 3 Comparisons of the annual average temperature and precipitation between the present study and the previous results in the northern Greater Khingan Mountains during the period from 1951 to 2007

\begin{tabular}{|c|c|c|c|c|}
\hline Areas & $\begin{array}{l}\text { Meteorological } \\
\text { Factors }\end{array}$ & $\begin{array}{l}\text { Comparisons } \\
\text { during the periods } \\
\text { from } 1989 \text { to } \\
2007 \text { and from } \\
1971 \text { to } 1988 \text {, } \\
\text { respectively }\end{array}$ & Distribution areas & $\begin{array}{l}\text { Climate ten- } \\
\text { dency rates } \\
\text { from } 1951 \\
\text { to } 2007\left({ }^{\circ} \mathrm{C} \text {, }\right. \\
\mathrm{mm} / 10 \mathrm{a})\end{array}$ \\
\hline \multirow{2}{*}{$\begin{array}{l}\text { Northeast China } \\
\text { (from the literature) }\end{array}$} & $\begin{array}{l}\text { Annual average } \\
\text { temperature } \\
\text { variation }\end{array}$ & $0.67-1.73$ & $\begin{array}{l}\text { Hulunbuir Pasture Land, } \\
\text { Greater Khingan Mountains, } \\
\text { Lesser Khingan Mountains, } \\
\text { Songnen Plain, Liaoxi Moun- } \\
\text { tain Land, Liaodong Peninsula, } \\
\text { Sanjiang Plain, Changbai } \\
\text { Mountains }\end{array}$ & 0.60 \\
\hline & $\begin{array}{l}\text { Annual precipi- } \\
\text { tation variation }\end{array}$ & $5.40-67.27$ & $\begin{array}{l}\text { Yilehuli Mountains, northern } \\
\text { Greater Khingan Mountains, } \\
\text { Lesser Khingan Mountains, } \\
\text { northern Changbai Mountains, } \\
\text { western Hulunbuir Pasture } \\
\text { Land, eastern Inner Mongolian } \\
\text { Plateau }\end{array}$ & -2.70 \\
\hline \multirow{2}{*}{$\begin{array}{l}\text { Northern Greater } \\
\text { Khingan Mountains } \\
\text { (from this article) }\end{array}$} & $\begin{array}{l}\text { Annual average } \\
\text { temperature } \\
\text { variation }\end{array}$ & 0.98 & $\begin{array}{l}\text { Northern Greater Khingan } \\
\text { Mountains }\left(50^{\circ} 10^{\prime}-53^{\circ} 30^{\prime} \mathrm{N} \text {, }\right. \\
\left.119^{\circ} 40^{\prime}-127^{\circ} 22^{\prime} \mathrm{E}\right)\end{array}$ & 0.54 \\
\hline & $\begin{array}{l}\text { Annual precipi- } \\
\text { tation variation }\end{array}$ & 13.26 & $\begin{array}{l}\text { Northern Greater Khingan } \\
\text { Mountains }\left(50^{\circ} 10^{\prime}-53^{\circ} 30^{\prime} \mathrm{N} \text {, }\right. \\
\left.119^{\circ} 40^{\prime}-127^{\circ} 22^{\prime} \mathrm{E}\right)\end{array}$ & 5.67 \\
\hline
\end{tabular}


On the one hand, the northern GKM are mainly primeval forests, with sparse population. The temperature variation is tightly correlated with the topographic changes, and the temperature increasing amplitude decreases gradually with the rising of terrain. On the other hand, outside the northern GKM, the latitude is relatively low, with the vegetation of forests, grasslands and farmlands. The artificial heating and urbanization on account of dense population may also contribute to the warming in this region. The annual precipitation varies slightly in different regions, with the maximum annual precipitation increasing amplitude of $3.5 \mathrm{~mm}$, which can almost be neglected. One can conclude that, in terms of the variations during two periods, the spatial variation amplitude of precipitation decreases gradually from high-latitude region to low-latitude region. This is due to the fact that, in the low-latitude regions, the artificial heating and urbanization have strong effects, the vegetation becomes sparser, and the landform transits from mountain lands to plain, i.e., the Northeast China Plain was formed. This may affect the general atmospheric circulation and the activities of cyclone. Compared with the results in $\mathrm{Fu}$ et al. (2009), the increasing amplitude of precipitation in the present study is smaller. This is because that the study regions are different and thus the average values of regional precipitation are different. On the whole, our research conclusions are reliable compared with the results in the other region.

\section{Conclusions}

In conclusion, the climate has been experiencing a significant change in the past 300 years in the northern GKM. There is an increasing trend of temperature. The precipitation increases slightly while the sunshine duration decreases. The variations of meteorological factors show distinctly regional difference.

(1) Decadal variations of climatic factors. In the northern GKM, the annual average temperature increases at a rate of $0.06^{\circ} \mathrm{C} / 10 \mathrm{a}(P \leqslant 0.01)$ during the period from 1707 to 2013. Specifically, in the 18th and 19th centuries, the annual average temperature in this region exhibits no obvious variations; in the 20th century, the temperature increases significantly, exceeding by $0.83^{\circ} \mathrm{C}$ than the value in the 19 th century, with the increasing amplitude of $0.32^{\circ} \mathrm{C} / 10 \mathrm{a}(\mathrm{P} \leqslant 0.01)$. The precipitation increased slightly on the whole, with the climate tendency rate of $0.79 \mathrm{~mm} / 10 \mathrm{a}(\mathrm{P} \leqslant 0.01)$. The precipitation decreased slightly in the 19 th century and increases in the 20th century, with the climate tendency rate of $6.04 \mathrm{~mm} / 10 \mathrm{a}(P \leqslant 0.01)$. During the period from 2001 to 2013, the precipitation is the greatest. Overall, the sunshine duration decreases, with the climate tendency rate of $-5.15 \mathrm{~h} / 10 \mathrm{a}(P \leqslant 0.01)$. The sunshine duration in the 19 th century is reduced by $2.75 \mathrm{~h}$ compared with the value in the 18 th century; in the 20 th century, the sunshine duration decreases significantly, with the climate tendency rate of $-23.27 \mathrm{~h} / 10 \mathrm{a}(\mathrm{P} \leqslant 0.01)$. From 2001 to 2013 , the sunshine duration exhibits a greatest decline, which is $100.14 \mathrm{~h}$ smaller than the value in the 20 th century.

(2) Abrupt change of climatic factors. The annual average temperature became warmer in 1866, 1960 and 1987, the precipitation increased suddenly in 1867 and 1927, and the sunshine duration decreased suddenly in 1866, 1960 and 1978. The strong sudden-change years of precipitation and sunshine duration basically coincide with the sudden-change years of average temperature, suggesting that in the mid-1860s, sudden change or transition of cli- 
mate really occurred in the northern GKM. The climatic factors all exhibit obvious periodic changes and show different alternations with different periods. The annual average temperature and sunshine duration both have the primary periods of 25 years, while the precipitation has a significant period of 20 years.

(3) Spatial characteristics of climatic factors. The annual average temperature is characterized by integrality in the northern GKM. The high-value distribution is concentrated along the line of Huma $\left(-0.7^{\circ} \mathrm{C}\right)$ and Heihe $\left(0.7^{\circ} \mathrm{C}\right)$, and the eigenvectors values decrease gradually to the west and north; The secondary-high-value distribution is at the center of Genhe. The results suggest that, the annual average temperature variability is great in these two regions of northern GKM, where the temperature changes are also sensitive. As to the precipitation, the high-value distribution is at the center of Elunchunqi, and the value decreases gradually to the north and east. The spatial distribution of sunshine duration is mainly the consistency-type. The maximum-value center is located at the center of Elunchunqi and the secondary high-value center is located at the center of Genhe.

\section{Discussion}

The previous studies on the climate changes on the time scale over a century indicate that, since the 1950s, the concentrations of carbon dioxide $\left(\mathrm{CO}_{2}\right)$ increase gradually under the influence of human activities and the earth has entered into an unprecedented era of climate changes (Stocker et al., 2013). Although the researchers now have accepted the viewpoint that the climate changes on a large time scale (for example, the global average temperature increases), the variation characteristics of various climatic factors on regional scale are still hard to determine (Millar et al., 2007). In other words, climate changes exhibit great uncertainties in different regions within a short time period (Walther et al., 2002), which is resulted from many reasons. In the present study, the annual average temperature in the northern GKM increases at a rate of $0.06^{\circ} \mathrm{C} / 10 \mathrm{a}(P \leqslant 0.01)$. Although the present results basically fit well with the latest research results (the annual average temperature increases at a rate of $\left(0.04-0.10^{\circ} \mathrm{C}\right) / 10 \mathrm{a}$ (Ren et al., 2014), they are different from the previous estimations on China's warming tendency over the past century. On the one hand, it indicates that our reconstructed meteorological data series in the northern GKM have high reliability (Tang et al., 2005); on the other hand, the differences originate from the differences in the study range, the length of climatic series and data sources. In the present study, the meteorological data before the 1950s were reconstructed based on the tree-ring data. Additionally, the data collected from the urban meteorological stations nearly for 60 years in the northern GKM may be affected by the enhanced urban heat island effect (He et al., 2013), leading to great uncertainties in the research on the climate changes in the northern GKM during the past 300 years. If the effects of urbanization on the data collected from the meteorological stations can be removed, the research on the mechanisms of climate changes in this region can be more accurate.

Generally, climate changes may lead to the changes in forest ecosystem structure and tree species. For example, the rising temperature can enhance the competitiveness of thermophilic species and contribute to their update and succession; however, the growth of chimonophilou plants may be suppressed (Xie et al., 2009; Wu et al., 2014). As the precipitation 
decreases, the growth of hygrophilous plants may be suppressed; even seriously, some leaves may fall or the tops may wither. This condition is conductive to the reproduction and invasion of some drought-enduring species. Climate changes can more easily change the plant's phenology and thus affect the dependency or competitiveness between species, i.e., climate changes can affect the reproduction and survival of species (Li et al., 2014; Wu et al., 2014). Besides, climate changes can change the plants' physiological and ecological characteristics and thereby play an important role in the formation of different species' durability, reproductive capacity and migration ability in the new system. In a word, due to climate changes, some species may exit from the original forest ecosystem while some new species invade the system, i.e., the structure and species composition of the original forest ecosystem can thus be changed (Liu et al., 2015). Similarly, climate changes (for example, warming, increasing precipitation and reduced sunshine duration) not only changed the forest vegetation and the distribution pattern suitable for tree species in the northern GKM, but also may impose profound impacts on economic developments, ecology and environment in this region. Warming leads to the prolonging of plant vegetation season and the reduced occurrence probability induced by chilling damages, which will bring the newborn forestry climatic resources and can provide the possibility for the adjustment of forestry production system (Gao et al., 2013). The increased precipitation means the increased probability of extreme precipitation event, which could bring adverse effects on forestry production and wetland ecosystem. Meanwhile, the decline in sunshine duration may be bad for the plants' photosynthetic efficiency and thus limited the release of the plants' potential productivity. As a consequence, how to cope with the effects of the uncertainties of climate changes on the research on the forest ecosystem in the northern GKM is a major subject in the present study, which still requires more in-depth, systematic and comprehensive studies.

\section{References}

Briffa K R, Schweingruber F H, Jones P D et al., 1998. Reduced sensitivity of recent tree-growth to temperature at high northern latitude. Nature, 391: 678-682.

Cai Qiufang, Liu Yu, Bao Guang et al., 2010. Tree-ring-based May-July mean temperature history for Lüliang Mountains, China, since 1836. Chinese Science Bulletin, 55(20): 2033-2039. (in Chinese)

Cook E R, D'Arrigo R D, Mann M E, 2002. A well-verified, multiproxy reconstruction of the winter north Atlantic oscillation index since AD 1400. Journal of Climate, 15(13): 1754-1764.

D’Arrigo R, Wilson R, Deser C et al., 2005. Tropical-north Pacific climate linkage over the past four centuries. Journal of Climate, 18: 5253-5265.

$\mathrm{Fu}$ Changchao, Liu Jiping, Liu Zhiming, 2009. Spacial and temporal differentiation rule of the climate change in northeast China in about 60 years. Journal of Arid Land Resources and Environment, 23(12): 60-65. (in Chinese)

Gao Tao, 2013. Climate influence of the atmospheric circulation and sea surface temperature on Larix gmelinii (Rupr.) Rupr. growth: Focus on Genhe region as an example [D]. Hohhot: Inner Mongolia Agricultural University. (in Chinese)

Ge Quansheng, Liu Jian, Fang Xiuqi et al., 2013. General characteristics of temperature change and centennial warm periods during the past 2000 years. Acta Geographica Sinica, 68(5): 579-592. (in Chinese)

Gou Xiaohua, Yang Tao, Gao Linlin et al., 2013. A 457-year reconstruction of precipitation in the southeastern Qinghai-Tibet Plateau. Chinese Science Bulletin, 58(11): 978-985. (in Chinese)

Guo Peipei, Yang Dong, Wang Hui et al., 2013. Climate change and its effects on climatic productivity in the Three-River Headwaters Region in 1960-2011. Chinese Journal of Ecology, 32(10): 2806-2814. (in Chinese)

He Wei, Bu Rencang, Xiong Zaiping et al., 2013. Characteristics of temperature and precipitation in northeastern China from 1961 to 2005. Acta Ecologica Sinica, 33(2): 519-531. (in Chinese)

Huang Rui, Xu Ligang, Liu Junmin, 2013. Research on spatio-temporal change of temperature in the Northwest 
Arid Area. Acta Ecologica Sinica, 33(13): 4078-4089. (in Chinese)

IPCC, 2013. Working Group I Contribution to the IPCC Fifth Assessment Report, Climate Change 2013: The Physical Science Basis: Summary for Policymaker [R/OL]. [2013-10-28]: 3-32.

Li Miao, Xia Jun, Chen Sheming et al., 2011. Wavelet analysis on annual precipitation around 300 years in Beijing area. Journal of Natural Resources, 26(6): 1001-1011. (in Chinese)

Li Shicheng, He Fanneng, Zhang Xuezhen, 2014. An approach of spatially-explicit reconstruction of historical forest in China: A case study in Northeast China. Acta Geographica Sinica, 69(3): 312-322. (in Chinese)

Liu Shirong, Dai Limin, Wen Yuan et al., 2015. A review on forest ecosystem management towards ecosystem services: Status, challenges, and future perspectives. Acta Ecologica Sinica, 35(1): 1-9. (in Chinese)

Lu Shanna, Wang Xiaochun, 2014. Growth climate response and winter precipitation reconstruction of Pinus Sylvestris var. Mongolicain Ali River of Greater Khingan Range. Journal of Northeast Normal University (Natural Science Edition), 46(2): 110-116. (in Chinese)

Millar C I, Stephenson N L, Stephens S L, 2007. Climate change and forests of the future: Managing in the face of uncertainty. Ecological Applications, 17(8): 2145-2151.

Qu Huihui, Zhao Huiying,Gong Lijuan, 2016. Climate data inversion for typical areas in northern of Greater Khingan Range for the last 300 years. Journal of Ecology and Rural Environment, 32(2): 184-191. (in Chinese)

Ren Guoyu, Ren Yuyu, Li Qingxiang et al., 2014. An overview on global land surface air temperature change. Advances in Earth Science, 29(8): 934-946. (in Chinese)

Shi Xinghe, Qin Ningsheng, Zhu Haifeng et al., 2010. May-June mean maximum temperature change during 1360-2005 as reconstructed by tree of Sabina Tibetica in Zaduo, Qinghai Province. Chinese Science Bulletin, 55(19): 1924-1931. (in Chinese)

Stocker T F, Dahe Q, Plattner G K, 2013. Climate Change 2013: The Physical Science Basis. In: Working Group I Contribution to the Fifth Assessment Report of the Intergovernmental Panel on Climate Change Summary for Policymakers (IPCC, 2013): 867-952.

Sun Fenghua, Yang Suying, Chen Pengshi, 2005.Climatic warming-drying trend in Northeastern China during the last 44 years and its effects. Chinese Journal of Ecology, 24(7): 751-755. (in Chinese)

Sun Yu, Wang Lili, Chen Jin et al., 2012. Reconstructing mean maximum temperatures of May-August from tree-ring maximum density in North Da Hinggan Mountains, China. Chinese Science Bulletin, 57(19): 1785-1793. (in Chinese)

Tang Guoli, Ren Guoyu, 2005. Reanalysis of surface air temperature change of the last 100 years over China. Climatic and Environmental Research, 10(4): 791-798. (in Chinese)

Walther G R, Post E, Convey P et al., 2002. Ecological responses to recent climate change. Nature, 416(6879): 389-395.

Wang Weiwei, Zhang Junhui, Dai Guanhua et al., 2012. Variation of autumn temperature over the past 240 years in Changbai Mountains of Northeast China: A reconstruction with tree-ring records. Chinese Journal of Ecology, 31(4): 787-793. (in Chinese)

Wu Shuang, Yan Xiaodong, Zhang Lijuan, 2014. The relationship between forest ecosystem emergy and forest ecosystem service value in China. Acta Geographica Sinica, 69(3): 334-342. (in Chinese)

Xie Chaozhu, Xie Lin, 2009. A high degree of concern about forest in climate change: The new mission of China's forestry development. Journal of Beijing Forestry University (Social Sciences), 8(3): 34-36. (in Chinese)

Yadav R R, Singh J, 2002. Tree-ring-based spring temperature patterns over the past four centuries in Western Himalaya. Quaternary Research, 57(3): 299-305.

Yang Danhui, 2012. New Trends of global climate change action and China's Negotiation Strategy. Journal of China University of Geosciences (Social Sciences Edition), 12(4): 8-13. (in Chinese)

Yu Dapao, Wang Shunzhong, Tang Lina et al., 2005. Relationship between tree-ring chronology of Larixol gensis in Changbai Mountains and the climate change. Chinese Journal of Applied Ecology, 16(1): 14-20. (in Chinese)

Zhang Jian, Man Zhimin, Song Jinxi et al., 2015. Sequence reconstruction and characteristics diagnosis of areal precipitation in the middle Yellow River from May to October during 1765-2010. Acta Geographica Sinica, 70(7): 1101-1113. (in Chinese)

Zhao Huiying, Wu Liji, Hao Wenjun, 2008. Influences of climate change to ecological and environmental evolvement in the Hulun Lake wetland and its surrounding areas. Acta Ecologica Sinica, 28(3): 1064-1071. (in Chinese)

Zhao Jingbo, Xing Shan, Zhou Qi, 2012. Frost and snow disaster and change periods in Guanzhong Plain in Ming Dynasty. Acta Geographica Sinica, 32(1): 81-86. (in Chinese)

Zhou Yiliang, 1991. China Greater Khingan Range Vegetation. Beijing: Science Press, 3-6. (in Chinese) 